\title{
Brain death and potential organ donors in neurocritical care mortality
}

\author{
$V_{\text {Spatenkova }}{ }^{*}$, O Bradac ${ }^{2}$, P Suchomel $^{3}$ \\ From ESICM LIVES 2015 \\ Berlin, Germany. 3-7 October 2015
}

\section{Introduction}

Neurocritical care mortality has potential for organ donation due to brain death.

\section{Objectives}

The aim of this study was to analyse the neurocritical care mortality rate and potential brain-dead organ donors.

\section{Methods}

We performed an analysis of a 10 -year prospective observational cohort database of 6138 patients $(58.2 \%$ of males, mean: age $55.9 \pm 14.7$ years, body weight $78.3 \pm 15.6 \mathrm{~kg}$, body mass index $26.9 \pm 4.7$, NICU stay $3.8 \pm 5.3$ days, Acute Physiology and Chronic Health Evaluation II score on admission $10.63 \pm 5.2$ ) admitted to a single adult neurointensive care unit (NICU). There were 3462 (56.4\%) patients (pts) with brain disease (stroke $43.2 \%$, tumour $31.1 \%$, trauma $13.6 \%$, epilepsy $3.8 \%$, hydrocephalus $3.4 \%$, infection $2.5 \%$, others $2.2 \%), 10.3 \%$ of pts had internal carotid artery stenosis (ACI), $32.6 \%$ of pts had spine diseases and $0.7 \%$ of pts had other disorders. Mean Glasgow Coma Scale on admission was $13.79 \pm 2.51$ and Glasgow Outcome scale upon discharge from NICU $3.97 \pm 1.13$.

\section{Results}

From 6138 admitted patients there were 159 (2.6\%) cases of NICU mortality with mean length of stay $9.21 \pm 10.2$. We found no differences in gender $(\mathrm{p}=0.804)$, but mortality rate was significantly higher in acute admissions $(\mathrm{p}<$ 0.001 ), primary admissions and secondary to 24 hours than secondary after 24 hours $(\mathrm{p}<0.001)$. Comparing the diagnoses, there was a significantly higher mortality rate in pts with brain diseases $(95.6 \%$ of deceased pts, $\mathrm{p}<0.001)$ than in ACI (0.6\%), spine (1.9\%) and from others (1.9\%).
From brain diseases there was significantly higher mortality in stroke pts $(67.1 \%)$ than in trauma $(17.8 \%)$, tumour (10.5\%), hydrocephalus (2\%), infection (2\%) and epilepsy $(0.7 \%)$, There were $23(14.5 \%)$ pts with clinical signs of brain death, of which 13 (56.5\%) became organ donors. Main reason of non-harvesting donors was hemodynamic instability (16.7\%) and family reluctance (12.5\%).

\section{Conclusions}

The results of our prospective databases showed that brain damage is the most common cause of mortality in neurointensive care; however there was a low proportion of clinical sign of brain death and not all potential donors were harvested.

\section{Authors' details}

${ }^{1}$ Regional Hospital, Neurocenter, Neurointensive Care Unit, Liberec, Czech Republic. ${ }^{2}$ Military University Hospital and First Medical School, Charles University, Department of Neurosurgery, Prague, Czech Republic. ${ }^{3}$ Neurocenter, Department of Neurosurgery, Liberec, Czech Republic.

Published: 1 October 2015

doi:10.1186/2197-425X-3-S1-A897

Cite this article as: Spatenkova et al: Brain death and potential organ donors in neurocritical care mortality. Intensive Care Medicine Experimental 2015 3(Suppl 1):A897. 